\title{
On the theory of innovative education
}

\author{
Tatyana Mikheeva ${ }^{1 *}$, and Viktoriya Pankova $^{2}$ \\ ${ }^{1}$ Don State Technical University, 344000, Rostov-on-Don, Russian Federation \\ ${ }^{2}$ Russian University of Transport, 127994, Moscow, Russian Federation
}

\begin{abstract}
Innovative education is a purposeful process of education and innovative training of a person, contributes to the development of his creative abilities, self-learning skills, self-improvement. The main objective of innovative education, formulated from the perspective of the mechanisms for the development of post-industrial civilization, is to ensure that the quality of human development is ahead of the way. As an important area of social activity, education outpaces other forms of social activity in its development. Innovative activity in education is a multicomponent social activity. Innovations in professional education express the integrative content of technical and technological, pedagogical, organizational and managerial, socio-economic innovations. These innovations ensure the innovative development of not only professional education, but also science, production, economy, management and the social sphere. Innovative processes in vocational education are put into practice in innovative education. Pedagogical innovations involve a personal and creative process of organizing the educational process, they cover the entire field of education. The contradiction between the demand of society for the quality of vocational training of university graduates, able to purposefully and effectively carry out self-education and selfpreparation for productive activities in the constantly changing external environment and the real practice of educational process in universities, actualizes the problem of self-education and self-training of students for innovative professional activities. Innovative process and innovation in connection with the implementation of new state educational standards in Russian secondary and higher education are gaining special status.
\end{abstract}

\section{Introduction}

In the context of the functioning of the market economy, the reform of Russian society requires active citizens of such a society, ready and able to participate in innovative organizational processes of any scale. At the same time, education changes its purpose: from a social state institution it becomes a universal means of cultural and economic transformation.

Innovation in education is a multi-component social activity that includes processes of:

- develop progressive innovations in the method of education and education,

- transforming the technology that implements them, as well as

\footnotetext{
*Corresponding author: mitata.m@yandex.ru
} 
- introducing them into the methodology and practical pedagogy in order to have a positive effect.

Innovation is seen not only in education, but also in otherareas. A. V. Khutorskoy emphasizes the unity of the three components of the innovation process: the creation, development and application of innovations [1]. Psychological and educational basis of the teacher's innovation are also being explored quite actively [2,3]. The main goal of innovative education, formulated from the perspective of the mechanisms of development of post-industrial civilization, is to ensure the advanced quality of human development. As an important area of social activity, education must outpace other forms of social activism in its development. Some researchers believe that the exception can be only fundamental science, which has always been and will be the main source of "educational potential" $[4,5]$.

Vocational education is aimed at developing a person's natural predisposition to learning and moving from conceptual thinking of reality to solving applied, social, managerial, organizational and technological tasks. The aim of innovative education is also to train a universal morally mature person, a competent specialist with a developed professional culture [6]. Such a specialist is a scientific style of thinking, is able to carry out innovative processes in vocational education[7].

\section{Materials and Methods}

The task of analyzing the process of innovative university education is solved. Theoretical methods of research and elements of psychological and educational basis of modeling of the educational process at the university were used.

\section{Results}

Human capital as a factor in the development of society is shaped by investments in nurturing, education, health, knowledge, information security, security and economic freedom of citizens, as well as in science and culture. Educational materials and educational technologies are the obligatory components of education content, which create the conditions for the formation of innovative thinking. Other conditions for this goal are:

- multi-critical staging and problem-solving,

- non-linear creative thinking,

- formulated and formed skills of information culture.

Teaching science presents innovative pedagogical activity as a focused professional work based on understanding of own experience, studying, changing and developing the educational process in order to achieve better results of work, learn new knowledge and sound practical decisions. It is believed that the sources of innovative processes in the practice of the educational institution are various factors:

- intuition / motivation of creative leader, teacher (group of teachers);

- the traditions and experiences of specific or regional educational organizations;

- regulatory documents;

- the needs of the faculty to work in a new way, and etc.

Innovation in education is understood as:

the implementation of the results of completed research and development into pedagogical practice, the development of other scientific and technological achievements;

- transforming intellectual property into a new or improved pedagogical product, implemented in practice or in the educational process;

- a new or improved educational process and related additional scientific research. 
When using innovative techniques in the educational process, the student actively engages in verbal communication with the teacher and the group, uses theoretical and practical language knowledge gained in the process of classroom and independent work with various sources of information. Innovative pedagogical technologies update, intensify the educational process by introducing active, analytical, communicative ways of learning. They provide a link between theory and the future specialty of the student, because they change the perception of teachers and students about educational activities and form the modern competences of future professionals.

The contradiction between the demand of society for the quality of vocational training of university graduates, able to purposefully and effectively carry out self-education and self-preparation for productive activities in the constantly changing external environment and the real practice of educational process in universities, actualizes the problem of selfeducation and self-training of students for innovative professional activities. The ability to self-educate and exercise self-training is presented today as a much-needed professional quality specialist and the most important condition for the development of professionally oriented thinking. In order for a specialist to maintain a high level of professional competence, he must participate in the process of continuing education throughout his life. To develop the readiness of students and graduates of universities to continuous education and self-education is now among the priorities facing the modern high school.

The teacher, based on knowledge of the psychological and educational basis of modeling the educational process, managing it at all stages of professional activity, does not need ineffective, external, powerful, authoritarian methods of management.

- motivational management through interest, personal significance, problem solving, success situation, etc.

- familiarity with patterns, models and methods of cognitive activity by demonstrating samples, solving cognitive problems, special task setting, algorithms and instructions, reflection, etc.

- adequate performance of cognitive activity and unobtrusive analysis of deficiencies.

The process of managing the assimilation of knowledge by students deserves special attention. Setting tasks and problem organization of thinking puts before the teacher the need to methodologically competently manage the thinking of students.

\section{Discussion}

Educational innovation, according to E.F. Zeer, is the result of activities that provide a new educational effect, including economic, managerial, social, environmental, health-saving and other aspects [8]. Innovation thus acts as a way to solve problems arising in different practical situations of functioning and development of educational processes.

The development of a model for the strategic development of high school reveals the ability of the organization, teachers and students to change, learn and self-improvement, which presents opportunities for the introduction of various integrative forms of science and education. The integration of science and education makes it possible to make a fairly radical transition from the educational process to the process of scientific and educational. Thus, master's programs allow to transform the structure of the study of the academic discipline into the structure of scientific research, which becomes effective for the formation and development of the creative abilities of students and improve the quality of professionalism of teachers. Innovations in vocational, including vocational education express the integrative content of technical and technological, pedagogical, organizational and management, socio-economic innovations. These innovations provide innovative development not only of vocational education, but also of science, production, economy, management and social sphere. Innovative processes in vocational education are put into 
practice in innovative education. In today's world, no state can oppose its interests to the interests of mankind.

As a result of globalization, the development of education in the world has entered the phase of international integration as a consequence of the internationalization of the educational sphere. A single educational space is being formed - the most effective form of solving the problems of international and planetary scale of the near and distant future. Higher education institutions are tasked not with unification, but in harmonizing educational programs (their "tuning" on each other). A. I. Vladimirov believes that "innovative activity in the university should be aimed at creating, implementing and obtaining economic, social, environmental and other types of effects from the implementation of innovative products" [9, p.11]. In the reform process, the academic graduate models and qualifications required by the market and society must play an important role along with the specific challenges that the academic community can address. The results of the training imply the determination of their levels of formation and are formulated in accordance with the current standards of higher education and the European qualification framework. They are measurable learning outcomes and are related to assessment methods [10,11].

The reforms also affected the evaluation of teachers' activities. The vocational education system in the information society is designed to develop such qualities of the learner as critical thinking, curiosity, openness, perseverance, etc., which will contribute to continuous learning and development throughout life [12].

It should be noted that the metaphor of a fragmented, clip-based image of consciousness replaces the image of the whole world and man, and this is manifested in the transition from the concept of fragmentary to the concept of integrative education, in which the idea of integration expresses an understanding of the single and indivised nature of man, together with an understanding of individuality there is a sense of belonging to everything that happens in the world.

The basis of the content of education is achieved by expanding and deepening the interdisciplinary knowledge of the specialist, focused on solving problems in scientific and organizational activities; professional, communicative and axiologic activities. Information is first of all knowledge, which forms the level of human capital of the country and, accordingly, the level of its development and the quality of life of the population. The ownership of information technology in all areas determines the level and quality of civil society and democracy in the country and, ultimately, the level and quality of national human capital, its effectiveness and competitiveness.

According to experts, for Russia as a whole it is necessary to profile the policy of human capital development taking into account critical factors in the information society, such as:

- continuity of education,

- readiness and willingness to apply modern information technologies in any area of human activity and to transform them on the basis of them,

Foreign language proficiency as a prerequisite for the ability to provide information services in the global market [13].

Interdisciplinary, according to E. A. Manushin, characterizes modern ideas about the fundamentality of vocational education and makes it rethink its content. At the same time, there is a serious pressure of the labor market, where there remains a high demand for specialists who have practical knowledge rather than fundamental (hence, not interdisciplinary) and practical knowledge. Nevertheless, interdisciplinary is the main, if not the only way to modernize the higher school, the way to innovation. The development of interdisciplinary modules in universities, especially for master's degrees, is becoming a major task that becomes a priority [14]. 


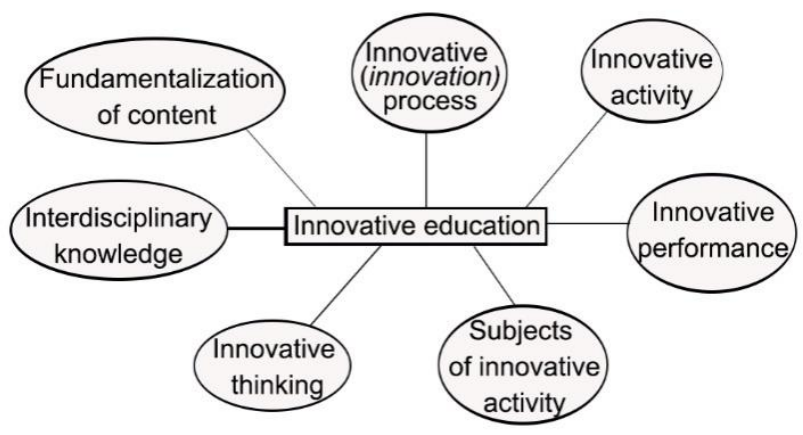

Fig. 1. Components of innovative education

Innovative teacher thinking and innovative student thinking are indicators of innovative education. The innovative thinking of the teacher is implemented in the classroom and is one of the indicators of the quality of his activities. Unfortunately, the innovative thinking of the student is not specially formed and practically absent in the teaching apparatus of the teacher. We understand the innovative thinking of the student as active motivation in learning, individual self-management to achieve the goals of learning. At the same time, the model of innovative education provides for education in the changing (in cognitive, sociocultural, economic sense) educational environment of the university. It is the innovative thinking of the student formed with the participation of the teacher can help to overcome the loads and smooth the stressful situations of modern post-industrial information civilization [15].

The contradiction between the demand of society for the quality of vocational training of university graduates, able to purposefully and effectively carry out self-education and self-preparation for productive activities in the constantly changing external environment and the real practice of educational process in universities, actualizes the problem of selfeducation and self-training of students for innovative professional activities. The ability to self-educate and exercise self-training is presented today as a much-needed professional quality specialist and the most important condition for the development of professionally oriented thinking. In order for a specialist to maintain a high level of professional competence, he must participate in the process of continuing education throughout his life. To develop the readiness of students and graduates of universities to continuous education and self-education is now among the priorities facing the modern high school.

\section{Conclusion}

Educational innovations involve the personal and creative process of organizing the educational process, they cover the entire field of education. The teacher, who implements the content of innovative education, shows, actualizes all the potential of the individual to find the optimal way out of the problem situation, creative transformation of professional activity, using innovative technologies and predicting the trajectory of their own professional growth and self-development. The strategic goal of the state education policy is to increase the accessibility of quality education that meets the requirements of innovative development of the state, the modern needs of society and each person. Sustainable transformation and development of the modern Russian economy is impossible without an innovative education system that contributes to the formation of the country's potential. 


\section{References}

1. A.V. Khutorskoy, Pedagogic Innovation: Methodology (Theory, Practice. UNC-DO. Moscow, 2005).

2. E.V. Karavayeva, Y.N. Kovtun, Tuning Journal for Higher Education 1, 187203(2013). doi: http://dx.doi.org/10.18543/tjhe-1(1)-2013pp187-202

3. N. Sergeev, Education and Society 2 (55), 82-97 (2013).

4. V.M. Prikhodko, N.V. Sazonova, N. Chechetkina, Higher education in Russia 11, 2127 (2005).

5. V.A. Slastenin, L.S. Podymova, Siberian Pedagogical Journal 1, 42-49 (2007).

6. N.M. Zolotareva, Education and Science 5 (114), 14-22(2014).

7. E.F. Zeer, Kazan Pedagogical Journal 2 (103), 9-22(2014).

8. E.F. Zeer, Education and science 5 (104), 65-83(2013).

9. A.I. Vladimirov, On the innovative activity of the university (Nedra, Moscow, 2012).

10. Yu.Yu. Milova, Management of the innovative activity of the higher educational institution, Economics, Management, Finance: proceedings of the III International Scientific Conference, 2014.

11. E.V. Egorov, S.A. Karev, Strategic management of innovative development of Russian universities. Information on http://futureruss.ru/expert_opinions/strategicheskoeupravlenie-innovacionnym-razvitiem-universitetov-rossii.html, last accessed 2021/01/15.

12. Rh. Koenig, Learning for keeps. Teaching the strategies essential for creating independent learners (ASCD, Alexandria, 2010).

13. T.B. Mikheeva, E.V. Murugova, Management of educational and cognitive activity of students within the framework of psychological and pedagogical aspect, Trends in the Development of Psycho-Pedagogical Education in the Conditions of Transitional Society (ICTDPP-2019), 07003, EDP Sciences, Les Ulis (2019). doi: https://doi.org/10.1051/shsconf/20197007003

14. E.A. Manushin, Science and Education 9, (2012).

15. A.M. Novikov, Postindustrial education (Egves, Moscow, 2008). 